\title{
Analysis of a Slug Calorimeter with a Curie Point
}

\author{
Jiann C. Yang \\ Thomas J. Ohlemiller
}

This publication is available free of charge from:

https://doi.org/10.6028/NIST.TN.2090

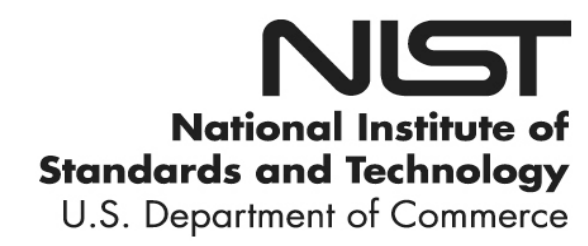




\title{
Analysis of a Slug Calorimeter with a Curie Point
}

\author{
Jiann C. Yang \\ Thomas J. Ohlemiller \\ Fire Research Division \\ Engineering Laboratory
}

This publication is available free of charge from:

https://doi.org/10.6028/NIST.TN.2090

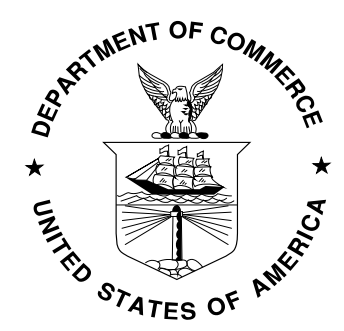

U.S. Department of Commerce

Wilbur L. Ross, Jr., Secretary

National Institute of Standards and Technology Walter Copan, NIST Director and Undersecretary of Commerce for Standards and Technology 
Certain commercial entities, equipment, or materials may be identified in this document in order to describe an experimental procedure or concept adequately. Such identification is not intended to imply recommendation or endorsement by the National Institute of Standards and Technology, nor is it intended to imply that the entities, materials, or equipment are necessarily the best available for the purpose.

National Institute of Standards and Technology Technical Note 2090

Natl. Inst. Stand. Technol. Tech. Note 2090, 11 pages (April 2020)

CODEN: NTNOEF

This publication is available free of charge from: https://doi.org/10.6028/NIST.TN.2090 


\begin{abstract}
A lump-capacitance heat transfer model was developed to model the operation of a slug calorimeter constructed of metal with a Curie point. The resulting formula has been successfully used to infer total heat flux to a metal structural member in a fire by temporally monitoring the internal temperature rise during the heat-up phase of the metal member (slug) with embedded thermocouples. The formula derived is applicable to slug calorimeters made from metals with or without a Curie point.
\end{abstract}

\title{
Key words
}

Fire; heat capacity; heat flux; heat transfer model. 


\section{Table of Contents}

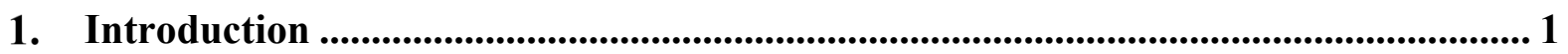

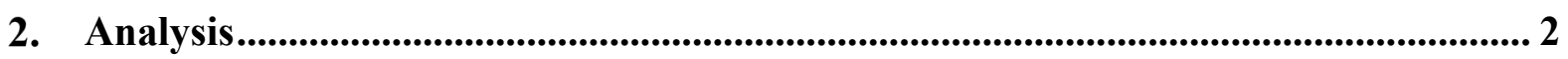

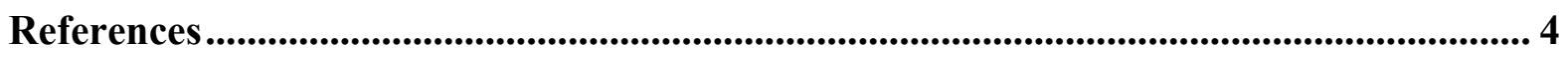

Appendix A: Supplemental Materials..........................................................................5

\section{List of Figures}

Fig. 1. An illustration of a $c_{p}-T$ curve with a Curie point. .......................................... 1

Fig. 2. A lump-capacitance heat transfer model............................................................... 2 


\section{Glossary}

$A \quad$ effective heat transfer area of the slug $\left(\mathrm{m}^{2}\right)$

$c_{v} \quad$ specific heat capacity at constant volume of the slug $(\mathrm{J} / \mathrm{kg}-\mathrm{K})$

$c_{p} \quad$ specific heat capacity at constant pressure of the slug $(\mathrm{J} / \mathrm{kg}-\mathrm{K})$

$m \quad$ mass of the slug $(\mathrm{kg})$

$P \quad$ pressure $(\mathrm{Pa})$

$\dot{q}^{\prime \prime} \quad$ total absorbed heat flux into the slug $\left(\mathrm{W} / \mathrm{m}^{2}\right)$

$Q \quad$ heat interaction between the surroundings and the slug (J)

$s \quad$ specific entropy of the slug $(\mathrm{J} / \mathrm{kg}-\mathrm{K})$

$T \quad$ temperature of the slug $(\mathrm{K})$

$t \quad$ time (s)

$u \quad$ specific internal energy of the $\operatorname{slug}(\mathrm{J} / \mathrm{kg})$

$v \quad$ specific volume of the slug $\left(\mathrm{m}^{3} / \mathrm{kg}\right)$

$\varepsilon \quad$ total surface emissivity of the slug (dimensionless)

$\sigma \quad$ Stefan-Boltzmann constant $\left(=5.670 \times 10^{-8} \mathrm{~W} / \mathrm{m}^{2}-\mathrm{K}^{4}\right)$ 


\section{Introduction}

A slug calorimeter, as the name implies, is a block of metal (slug) with embedded thermocouples to measure the slug temperature. The slug could be in the shape of a rectangular slab or a cylinder. A slug calorimeter is typically coated with a flat black paint with high absorptivity across the visible and infrared to keep the absorbed flux as close to the incident flux from a fire as possible. It is the incident flux which is generally the quantity of interest since the calorimeter is a substitute for some other real object exposed to the fire, and one wants to know the heat load on that object. One infers the average heat flux to the slug surface from its temperature rise history. These slug calorimeters are expected to heat up rapidly in a fire, approaching the effective radiation temperature of the surroundings. Thus, they can only provide heat flux information in a fire test until the effective radiation temperature is reached.

This short note provides a detailed analysis of a slug calorimeter constructed of a type of metal that has a Curie point. The constant-pressure heat capacities for most metals vary continuously with temperature. However, for some metals (e.g., steel or nickel, the latter being preferred in slug calorimetry for its higher thermal conductivity), there exists a Curie point at which the heat capacity changes abruptly (see Figure 1 for illustration). A fire could easily heat the slug well beyond the Curie temperature, so this needs to be accounted for in the data analysis.

In this note, we derive an expression for the total heat flux to the slug (averaged over its surface), which could be applied equally well to cases with or without a Curie point in the $c_{p}-T$ curve.

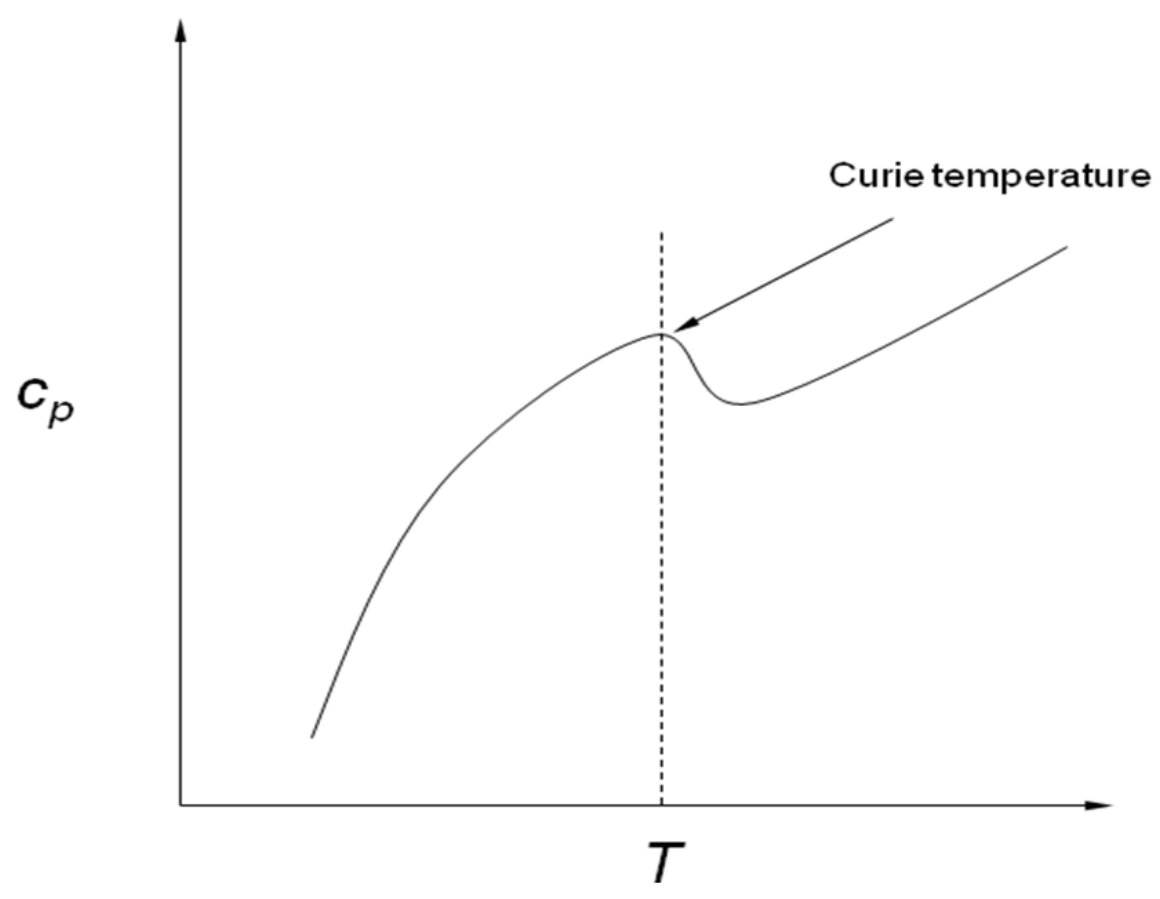

Fig. 1. An illustration of a $c_{p}-T$ curve with a Curie point. 


\section{Analysis}

The analysis is based on the application of a lumped-capacitance heat transfer model [1] to the slug. Figure 2 is a schematic of an arbitrarily shaped slug with a uniform, time-dependent temperature. The following treatise follows closely to that given in Bird et al. [2]. The First Law of Thermodynamics applied to the system in Fig. 2 gives ${ }^{1}$.

$$
m \mathrm{~d} u=\delta Q
$$

From the fundamental equation of thermodynamics [3],

$$
\mathrm{d} u=\left(\frac{\partial u}{\partial s}\right)_{v} \mathrm{~d} s+\left(\frac{\partial u}{\partial v}\right)_{s} \mathrm{~d} v=T \mathrm{~d} s-P \mathrm{~d} v
$$

Also,

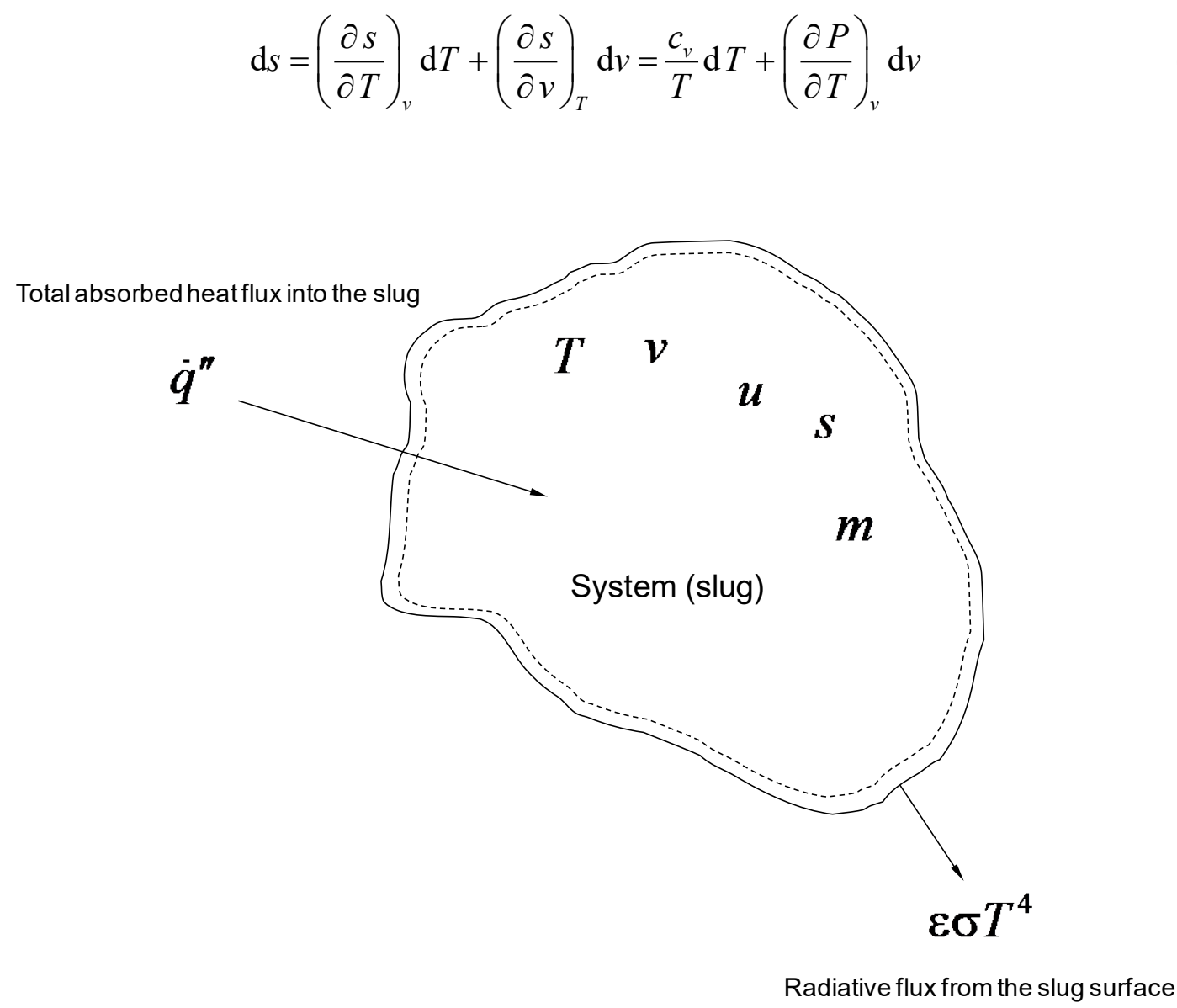

Fig. 2. A lump-capacitance heat transfer model.

\footnotetext{
${ }^{1}$ The symbol $\delta$ is used here to denote a differential change of a path function, whereas $d$ is for a differential change of a state function.
} 
Substituting Eq. (3) into (2),

$$
\mathrm{d} u=\left[-P+T\left(\frac{\partial P}{\partial T}\right)_{v}\right] \mathrm{d} v+c_{v} \mathrm{~d} T
$$

Substituting Eq. (4) into Eq. (1),

$$
m\left[-P+T\left(\frac{\partial P}{\partial T}\right)_{v}\right] \mathrm{d} v+m c_{v} \mathrm{~d} T=\delta Q
$$

Since

$$
c_{v}=c_{p}+\frac{T\left(\frac{\partial v}{\partial T}\right)_{P}^{2}}{\left(\frac{\partial v}{\partial P}\right)_{T}}
$$

For metals, the last term in Eq. (6) is very small. Hence, $c_{v} \approx c_{p}$, and dividing Eq. (5) by dt,

$$
m\left[-P+T\left(\frac{\partial P}{\partial T}\right)_{v}\right] \frac{\mathrm{d} v}{\mathrm{~d} t}+m c_{p} \frac{\mathrm{d} T}{\mathrm{~d} t}=\frac{\delta Q}{\mathrm{~d} t}
$$

Assuming the thermal expansion coefficient of the slug is small, the slug volume can be considered constant, and Eq. (7) becomes

$$
m c_{p} \frac{\mathrm{d} T}{\mathrm{~d} t}=\frac{\delta Q}{\mathrm{~d} t}
$$

or

$$
m c_{p} \frac{\mathrm{d} T}{\mathrm{~d} t}=A\left[\dot{q}^{\prime \prime}-\varepsilon \sigma T^{4}\right]
$$

The first term inside the bracket on the right-hand side is the total absorbed heat flux onto the slug, which consists of radiative and convective fluxes, and the second term is the radiative flux from the slug surface. Hence,

$$
\dot{q}^{\prime \prime}=\left[\frac{m}{A} c_{p} \frac{\mathrm{d} T}{\mathrm{~d} t}\right]+\varepsilon \sigma T^{4}
$$


By measuring the temporal variation of the slug temperature, the total absorbed heat flux onto the slug can be obtained using Eq. $(10)^{2}$. This equation finds its application in extracting the total heat flux from the average rate of internal temperature rise of a slug calorimeter with or without a Curie point exposed to a fire. Equation (10) has been successfully used to infer the total heat flux from a fire to a structural element [4]. Since Eq. (10) was used in [4] without any derivation presented, we feel that in retrospect, detailed analysis should have been provided in view of current interest in measuring fire exposure to structural elements and other slug calorimeter applications. This note is to fulfill the purpose.

\section{References}

[1] Incropera FP, DeWitt DP (1985) Fundamentals of Heat and Mass Transfer, 2nd edition (John Wiley and Sons).

[2] Bird RB, Stewart WE, Lightfoot EN (1960) Transport Phenomena (John Wiley and Sons).

[3] Modell M, Reid RC (1974) Thermodynamics and Its Applications (Prentice-Hall).

[4] Hamins A, Maranghides A, McGrattan KB, Johnsson EL, Ohlemiller TJ, Donnelly MK, Yang JC, Mulholland GW, Prasad KR, Kukuck SR, Anleitner R, McAllister TP (2005) Federal building and fire safety investigation of the World Trade Center disaster: experiments and modeling of structural steel elements exposed to fire (National Institute of Standards and Technology, Gaithersburg, MD), NIST NCSTAR 1-5B.

\footnotetext{
2 See supplemental materials in Appendix A for additional discussion.
} 


\section{Appendix A: Supplemental Materials}

In the analysis, if one were to directly express the internal energy of the slug simply in terms of the product of $m c_{p} T$ and to expand its time derivative into two terms to account for the temperature dependence of $c_{p}$.

$$
m \frac{\mathrm{d}\left(c_{p} T\right)}{\mathrm{d} t}=m \frac{\mathrm{d}\left(c_{p} T\right)}{\mathrm{d} T} \frac{\mathrm{d} T}{\mathrm{~d} t}=m T \frac{\mathrm{d} c_{p}}{\mathrm{~d} T} \frac{\mathrm{d} T}{\mathrm{~d} t}+m c_{p} \frac{\mathrm{d} T}{\mathrm{~d} t}
$$

In this case, Eq. (10) would be derived incorrectly as

$$
\dot{q}^{\prime \prime}=\left[\frac{m T}{A} \frac{\mathrm{d} c_{p}}{\mathrm{~d} T}+\frac{m c_{p}}{A}\right] \frac{\mathrm{d} T}{\mathrm{~d} t}+\varepsilon \sigma T^{4}
$$

In addition, there is a problem in using Eq. (A2) if the system being heated has a Curie point. A sign change in $\mathrm{d} c_{p} / \mathrm{d} T$ occurs, which would result in a sudden unrealistic decrease in $\dot{q}^{\prime \prime}$ beyond the Curie point. The above detailed analysis clearly shows that the term that contains $\mathrm{d} c_{p} / \mathrm{d} T$ in Eq. (A2) does not exist. The incorrectness of Eq. (A2) is further masked by the fact that Eq. (10) is recovered from Eq. (A2) for constant $c_{p}$. The correct expression for $\dot{q}^{\prime \prime}$ should be Eq. (10), which applies irrespectively of whether $c_{p}$ is a function of $T$ or not (with or without a Curie point). 